\title{
Growth Termination and Multiple Nucleation of Single-Wall Carbon Nanotubes Evidenced by in Situ Transmission Electron Microscopy
}

Zhang, Lili; He, Maoshuai; Hansen, Thomas Willum; Kling, Jens; Jiang, Hua; Kauppinen, Esko I.; Loiseau, Annick; Wagner, Jakob Birkedal

\section{Published in: \\ A C S Nano}

Link to article, DOI:

10.1021/acsnano.6b05941

Publication date:

2017

Document Version

Peer reviewed version

Link back to DTU Orbit

Citation (APA):

Zhang, L., He, M., Hansen, T. W., Kling, J., Jiang, H., Kauppinen, E. I., Loiseau, A., \& Wagner, J. B. (2017). Growth Termination and Multiple Nucleation of Single-Wall Carbon Nanotubes Evidenced by in Situ

Transmission Electron Microscopy. A C S Nano, 11(5), 4483-4493. https://doi.org/10.1021/acsnano.6b05941

\section{General rights}

Copyright and moral rights for the publications made accessible in the public portal are retained by the authors and/or other copyright owners and it is a condition of accessing publications that users recognise and abide by the legal requirements associated with these rights.

- Users may download and print one copy of any publication from the public portal for the purpose of private study or research.

- You may not further distribute the material or use it for any profit-making activity or commercial gain

- You may freely distribute the URL identifying the publication in the public portal 
This document is confidential and is proprietary to the American Chemical Society and its authors. Do not copy or disclose without written permission. If you have received this item in error, notify the sender and delete all copies.

\section{Growth Termination and Multiple Nucleation of Single-Wall Carbon Nanotubes Evidenced by In Situ Transmission Electron Microscopy}

\begin{tabular}{|r|l|}
\hline Journal: & ACS Nano \\
\hline Manuscript ID & nn-2016-05941e.R3 \\
\hline Manuscript Type: & Article \\
\hline Date Submitted by the Author: & $\mathrm{n} / \mathrm{a}$ \\
\hline Complete List of Authors: & $\begin{array}{l}\text { Zhang, Lili; Danmarks Tekniske Universitet, Center for Electron Nanoscopy } \\
\text { He, Maoshuai; School of Materials Science and Engineering,; ONERA, } \\
\text { Laboratoire d'Étude des Microstructures } \\
\text { Hansen, Thomas; denmark, Technical University of Denmark } \\
\text { Kling, Jens; Technical University of Denmark, Center for Electron } \\
\text { Nanoscopy } \\
\text { Jiang, Hua; Aalto University, Department of Applied Physics } \\
\text { Kauppinen, Esko; Aalto University School of Science, Applied Physics } \\
\text { Loiseau, Annick; (LEM), Laboratoire d'Étude des Microstructures } \\
\text { Wagner, Jakob; Danmarks Tekniske Universitet, Center for Electron } \\
\text { Nanoscopy }\end{array}$ \\
\hline
\end{tabular}




\title{
Growth Termination and Multiple Nucleation of Single-
} Wall Carbon Nanotubes Evidenced by In Situ Transmission Electron Microscopy

\author{
Lili Zhang, ${ }^{* \dagger}$ Maoshuai He, ${ }^{\ddagger} \S$ Thomas W. Hansen, ${ }^{\dagger}$ Jens Kling,${ }^{\dagger}$ Hua Jiang, ${ }^{\perp}$ Esko I. Kauppinen, ${ }^{\perp}$ \\ Annick Loiseau, ${ }^{\S}$ Jakob B. Wagner ${ }^{*} \dagger$ \\ ${ }^{\dagger}$ Technical University of Denmark, Center for Electron Nanoscopy, Fysikvej 307, 2800 Kgs. Lyngby, \\ Denmark \\ $\$$ School of Materials Science and Engineering, Shandong University of Science and Technology, \\ 266590 Qingdao, People’s Republic of China \\ ${ }^{\perp}$ Department of Applied Physics, Aalto University School of Science, P.O. Box 15100, FI-00076 \\ Aalto, Finland \\ ${ }^{\S}$ Laboratoire d'Étude des Microstructures, ONERA-CNRS, BP 72, 92322 Châtillon CEDEX, France \\ *Address correspondence to lilizha@,dtu.dk. Jakob.wagner@,cen.dtu.dk.
}




\begin{abstract}
In order to controllably grow single-wall carbon nanotubes (SWCNTs), it is required a better understanding of the growth processes and how they are influenced by external parameters such as catalyst and gaseous environment. Here, we present direct evidence of growth termination of individual SWCNTs and successive growth of additional SWCNTs on Co catalyst particles supported on MgO by means of environmental transmission electron microscopy (TEM). Such in situ observations reveal the plethora of solid carbon formations at the local scale while it is happening and thereby elucidate the multitude of configurations resulting from identical external synthesis conditions, which should be considered in the quest for controlled SWCNT growth. Using $\mathrm{CO}$ and a mixture of $\mathrm{CO}$ and $\mathrm{H}_{2}$ as carbon sources, we show that the growth of SWCNTs terminates with a reduced tube-catalyst adhesion strength. Two main reasons for the cessation are proposed: insufficient active carbon species and a certain amount of stresses exerted at the tube-catalyst interface. Interestingly, it was observed that catalyst particles stayed active in terms of nucleating additional solid carbon structures after growth termination of the first SWCNT. These observations elucidate the importance of an in-depth understanding of the role of catalysts and carbon sources in the continued growth of SWCNTs. Furthermore, it serves as a guide for further control of carbon nanostructure synthesis via catalyst engineering and synthesis optimization.
\end{abstract}

\title{
KEYWORDS
}

Single-Wall Carbon Nanotube, Catalytic Growth, Termination Mechanism, Multiple Nucleation, In Situ, Transmission Electron Microscopy

Controlling the structure and thereby properties of single-wall carbon nanotubes (SWCNTs) during synthesis has become a central issue in nano-electronics applications. ${ }^{1}$ In recent years, much effort has 
been devoted to designing novel catalysts ${ }^{2-3}$ and optimizing synthesis parameters. ${ }^{4}$ As for chemical vapor deposition processes, the choice of catalysts and carbon source mainly manifest their roles on the SWCNT structures at the initial and final growth stages. ${ }^{6}$ A catalyst nanoparticle usually acts as template in the nucleation of a carbon dome, ${ }^{5-8}$ which can eventually lift off the surface of a particle as a cap. $^{9-11}$ The particle-carbon bonds at the growth front at the cap/tube also prevent their closure by carbon-carbon bonding. ${ }^{12}$ Additionally, a cap can only elongate to form a tube by further incorporating active carbon species (e.g., $\mathrm{C}_{2}$ dimers $^{13}$ ) to its open edge which is attached to a particle. If the carbon source is cut off or pulsed, the CNT structure ${ }^{14-16}$ can be distorted around the tube-catalyst interface and result in growth termination ${ }^{17}$ or the formation of a disordered band. ${ }^{18}$ In order to further elucidate the local impact on the growth mechanisms including growth termination, the growth of individual SWCNTs has been monitored directly in the present work.

Remarkable progress has been made in the studies of the termination mechanisms, mainly for multiwall CNTs (MWCNTs) or a mixture of MWCNTs and SWCNTs on the macroscale, but the conclusions remain controversial or ambiguous. For instance, Reilly and Whitten ${ }^{19}$ proposed that encapsulation of the catalysts by amorphous carbon causes the growth termination of CNT arrays. Etchants, such as $\mathrm{H}_{2} \mathrm{O}$ vapor, $\mathrm{O}_{2}$, or $\mathrm{H}_{2}$ radicals, are thus widely used to increase the CNT growth efficiency, ${ }^{17,20-21}$ indicating that the catalyst activity can be improved by etching amorphous carbon at the catalyst surface. In contrast, Amama et al. ${ }^{22}$ argued that the growth termination of vertically aligned CNT arrays resulted from Ostwald ripening of catalyst particles, which could be inhibited by the addition of water. Except for catalyst deactivation, previous studies also attribute growth termination to reduced carbon diffusion or supply during CNT growth. For example, the growth of vertically aligned CNT arrays usually follow an exponential decay model ${ }^{23}$ but sometimes also show an abrupt termination, ${ }^{24}$ due to the presence of amorphous carbon at a later stage of the CNT growth limiting the 
local supply of carbon atoms to the catalysts. Based on the few works on the growth termination of SWCNTs, Maruyama et $a .^{25}$ found that the growth of a SWCNT vertical film obeys a similar exponential decay model, possibly due to the diffusion resistance of the carbon source through a CNT film, catalyst poisoning and SWCNT burning by residual oxidant gases. They further clarified that the diffusion of the carbon source to the base of the vertically aligned SWCNTs was severely limited compared to MWCNT arrays; ${ }^{26}$ Picher et al. ${ }^{27}$ used in situ Raman measurements to investigate the selfdeactivation of SWCNTs. They claimed that defect-healing at the tube-catalyst interface is limited by an improper combination of growth temperature and precursor partial pressure.

Due to the complex chemical processes of CNT growth and insufficient details given by optical techniques or post-synthesis observations, it remains a challenge to clarify the above controversial issues. As a powerful approach for characterizing nanostructures during the growth of CNTs, in situ transmission electron microscopy (TEM) reveals more details about the roles of catalysts on MWCNT termination. $^{28-29}$ However, direct evidence accounting for the growth termination of individual SWCNTs has been lacking. In the present study, we monitored the growth kinetics of individual SWCNTs from $\mathrm{Co} / \mathrm{MgO}$ catalysts in situ by means of environmental TEM (ETEM). An image $\mathrm{C}_{\mathrm{s}^{-}}$ corrected FEI Titan microscope equipped with a differential pumping system allows us to visualize the detailed structures of catalysts and CNTs at high resolution. ${ }^{30}$ A MEMS based heating holder provides precise temperature control with stability in the micro kelvin range. The in situ growth of SWCNTs at low CO pressure revealed a plethora of solid carbon structures, although mostly based on single layer carbon variants. The local impact from the environment (structural and environmental) apparently has a large influence on the growth mechanisms and the success rate of longer SWCNTs and suggests that unravelling the complexity of the growth mechanisms is key to exploit the prospects of tailored SWCNT growth. In order to explore the roles of catalyst and carbon supply on SWCNT termination, 
SWCNTs grown under $\mathrm{CO}$ at varying pressures and mixtures of $\mathrm{CO} / \mathrm{H}_{2}$ were compared. Reducing tube-catalyst adhesion strength by necking and broadening of the tube diameter acts as the ways of SWCNT growth cessation. In addition, we show that catalysts remain active in successively forming new SWCNTs, suggesting that other factors than the self-deactivation of catalysts result in the growth termination of SWCNTs.

\section{RESULTS}

\section{Catalytic growth of fullerenes}

The nucleation of a cap from a catalyst particle can be considered as the initial step for SWCNT growth. However, if a SWCNT close its growth edges at the initial stage, which originally bonded to a catalyst particle, a spherical cage (named fullerene) is generated from the catalyst particle instead of growing into a cylindrical tube. ${ }^{31}$ The details of the chemical vapor deposition process of fullerenes ${ }^{32-33}$ have rarely been reported before.

Prior to SWCNT growth, the $\mathrm{Co} / \mathrm{MgO}$ catalyst sample (see Materials and Methods and Figure $\mathrm{S} 1$ in Supporting Information) was first heated to $300{ }^{\circ} \mathrm{C}$ inside the TEM in the presence of 1.6 mbar $\mathrm{CO}$ to in situ form nanoparticles on the crystalline MgO surface (Figure S2 in Supporting Information). After that, the temperature was increased to $700{ }^{\circ} \mathrm{C}$, and then the pressure of $\mathrm{CO}$ was raised to 5.3 mbar to trigger the subsequent growth of SWCNTs. Figure 1 depicts in situ TEM observations of the formation and detachment of a fullerene from a catalyst particle (highlighted by the sketches below). A graphene dome was initially bound to the tip of the $1.6 \mathrm{~nm}$ particle $(0 \mathrm{~s})$, from which a spherical cap was lifted off (12 s). As it is a projected image, it is challenging to distinguish between an open cap and a closed fullerene. The dome subsequently detached itself from the particle and became a fullerene with a diameter similar to that of the particle (the diameter would indicate $\mathrm{C}_{240}$ fullerene, in case it would be a defect-free structure). Note that fullerene structures were distinguished from SWCNTs based on a 
series of images. The stable configurations lying on $\mathrm{MgO}$ supports also benefit for the structure identification. Interestingly, the particle was able to nucleate another dome and lift off a cap at the same site $(70 \mathrm{~s})$. These double nucleation processes from the same particle possess a tangential connection, different from the perpendicular nucleation of several SWCNTs from the local area of a large catalyst particle, ${ }^{34-36}$ indicating that the catalyst remains active for an extended period. During the above process, the crystalline orientation of the catalyst particle exhibits negligible changes $\left(<5^{\circ}\right.$ within $\left.70 \mathrm{~s}\right)$, as represented in the sequence of TEM images and inserted fast Fourier transforms (FFT) in Figure 1. By measuring the lattice fringes of the particle (calibrated by the lattice fringes of the support $\mathrm{MgO}$ ), cobalt carbide phase $\left(\mathrm{Co}_{3} \mathrm{C}\right.$ or $\left.\mathrm{Co}_{2} \mathrm{C}, \mathrm{d} \approx 0.23 \mathrm{~nm}\right)$ rather than metallic Co phase $\left(\mathrm{d}_{\max } \approx 0.20 \mathrm{~nm}\right)$ was determined. In agreement with Sharma's work, ${ }^{11}$ such carbide phase might take as the active phase for catalytic growth of carbon nanomaterials. Therefore, the morphological evolution might be ruled out as a possible cause for the growth termination. ${ }^{28}$
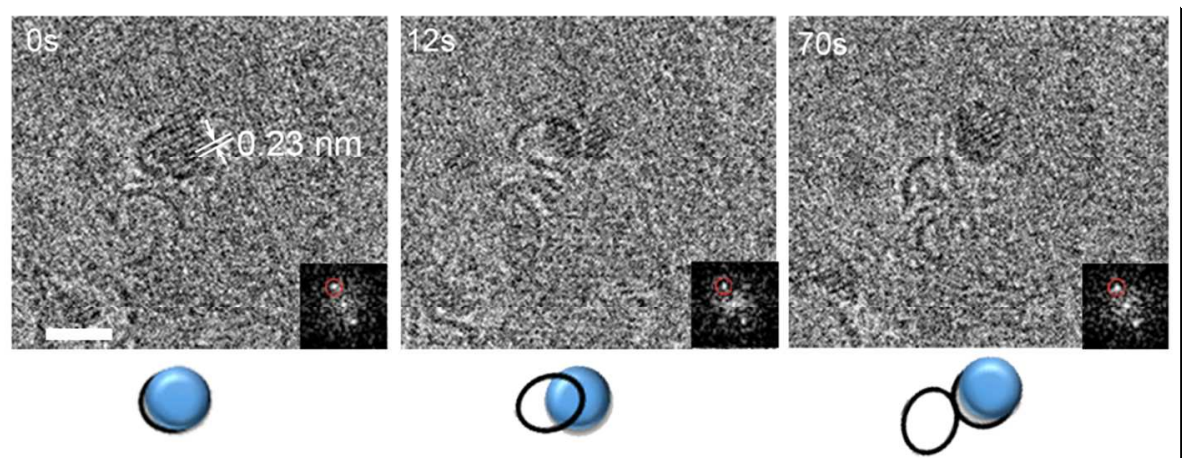

Figure 1. TEM images and sketches (below) of nucleation and dissociation processes of caps (fullerenes) on a crystalline particle. The FFT of the high-contrast particle is inserted in each image. The scale bar is $2 \mathrm{~nm}$.

Fullerene formation requires the formation of pentagons during the growth process. That means the formation of carbon pentagons would trigger a cap formation and closure. ${ }^{12}$ It is reported, that high $\mathrm{CO}$ 
pressures ( $\geq 1000$ mbar) and thermodynamic processes are usually needed to promote the CO disproportionation reaction to grow SWCNTs efficiently. ${ }^{37-39}$ For example, if the CO pressure was slightly increased by tens or hundreds of mbar from atmospheric pressure, the yield and selectivity of SWCNTs were enhanced significantly. ${ }^{37,40-42}$ Therefore, the CO disproportionation reaction is believed to be the rate-limiting step for tube growth. ${ }^{38}$ Here under a relatively low CO pressure $(<10$ mbar $)$ in the ETEM environment, the disproportionation rate of $\mathrm{CO}$ is supposed to be very low, causing nonconsecutive incorporation of carbon atoms in the growth of a CNT (lack of active carbon species) at the vicinity of the particle. Carbon pentagons, vacancies or other defects then accumulated around the tubecatalyst interface, and finally resulted in a cap closure and a separation from the particle. The formation of fullerenes can be regarded as the cessation of an extreme short SWCNT. The exact structure of these fullerenes does not affect the presented mechanism. The detachment of caps from the catalysts can be observed repeatedly in this work (see Figure S3 in Supporting Information), and it does not seem limited to a specific condition. This implies, that a low CO pressure is one of the main reasons for the inefficient SWCNT growth.

\section{Growth termination of a short SWCNT}




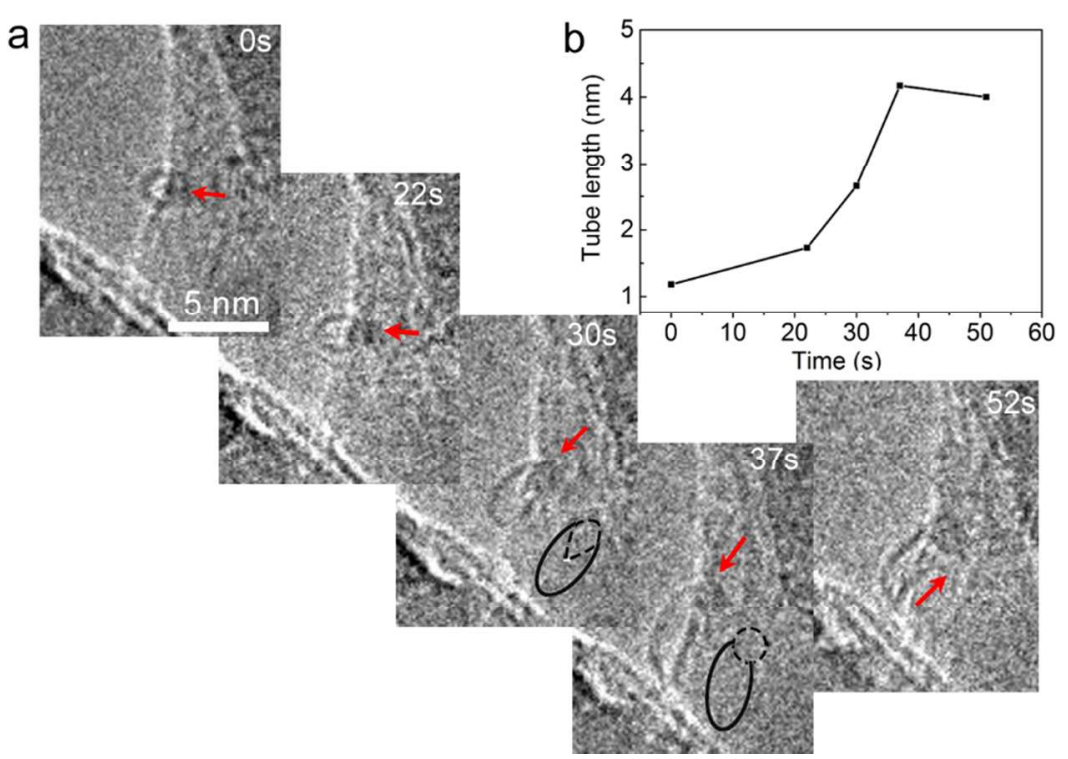

Figure 2. The growth and termination of a short SWCNT $(<5 \mathrm{~nm})$. (a) A series of time-resolved TEM images showing the growth process of a SWCNT over a period of $52 \mathrm{~s}$. The inserted sketches at 30 and 37 s show the relationship between the tube and the particle outlined by a dotted circle. The red arrows indicate the growth direction of the tube, and at $52 \mathrm{~s}$, the tube seems to shrink back to the particle in an opposite direction. (b) A profile of the tube length vs. time.

With a $\sim 20 \%$ higher $\mathrm{CO}$ pressure but using the same $\mathrm{Co} / \mathrm{MgO}$ catalyst system as above, a series of time-resolved TEM images were captured at $700{ }^{\circ} \mathrm{C}$ and $6.5 \mathrm{mbar} \mathrm{CO}$, representing the growth and termination processes of a SWCNT (Figure 2). From the first frame acquired (here defined as $0 \mathrm{~s}$ ), we can see that a lift-off cap is tangentially ${ }^{7}$ connected to a particle. In a time frame of up to $30 \mathrm{~s}$, a SWCNT with a diameter about $1.6 \mathrm{~nm}$ was formed. Its growth direction changed as marked by red arrows, suggesting the formation of a weak metal-carbon or metal-substrate adhesion strength. Meanwhile, the particle restructured to a droplet-like shape and was partially encapsulated in the tube (see the inserted sketch, the dotted circle outlines the particle). The SWCNT soon stopped growing at $37 \mathrm{~s}$, after reaching a total length of $4.2 \mathrm{~nm}$. At the same time, the catalyst particle reverted back to a 
spherical shape. The sketch inserted shows the way the SWCNT terminated by necking down the tubecatalyst interface, where the tube diameter was reduced. Note that the SWCNT continued growing even though the particle changed its morphology (30 s) and tended to change the catalyst-support interaction. ${ }^{28}$ In other words, there must be a reason other than the change of catalyst morphology that hinders the continued growth of the SWCNT. The length of the SWCNT was measured based on the in situ observations, and the tube growth rate can be calculated from the profile in Figure $2 \mathrm{~b}$. It was found that the growth rate is not constant, and a rough calculation indicates that about 10 carbon atoms were integrated into the tube per second at the early growth stage $(\sim 0.05 \mathrm{~nm} / \mathrm{s})$ and about 40 carbon atoms at the late growth stage $(\sim 0.2 \mathrm{~nm} / \mathrm{s})$. The growth terminated just after the abrupt increase of the growth rate. After that the tube length shrunk slightly (52 s), meaning that the interface was not strongly bonded. At the atomic level, the accelerated growth (or a fast cap lift-off), relative to a limited carbon supply rate to the catalyst particle, leads to a reduced catalyst-tube adhesion strength, ${ }^{31,43}$ which does not allow defect healing and finally creates more defects and forms a necking interface. Although simulation results suggest that the slower carbon supply rate should promote the defect healing, ${ }^{43}$ the tube growth rate at which carbon atoms are incorporated into the growing structures is too slow in this study (an average growth rate of around $0.1 \mathrm{~nm} / \mathrm{s}$ ), hindering the efficient defect healing. This fact suggests that a possible reason for SWCNT termination would be a dynamic imbalance of the faster consumption of carbon atoms for the tube growth and a limited provision of active carbon species at the growth front.

\section{Multiple nucleation of SWCNTs and their structural evolution}

The multiple nucleation of caps from the same catalyst particle signifies the growth termination of the initial SWCNT/cap, i.e., the broken of the interfacial carbon-metal bonds (the reduced tube-catalyst adhesion strength). In order to explore the role of catalysts on the growth termination of SWCNTs in 
detail, we have grown SWCNTs under a CO pressure of 7.6 mbar (an increase by $40 \%$ compared to the sequential growth of fullerenes in Figure 1).
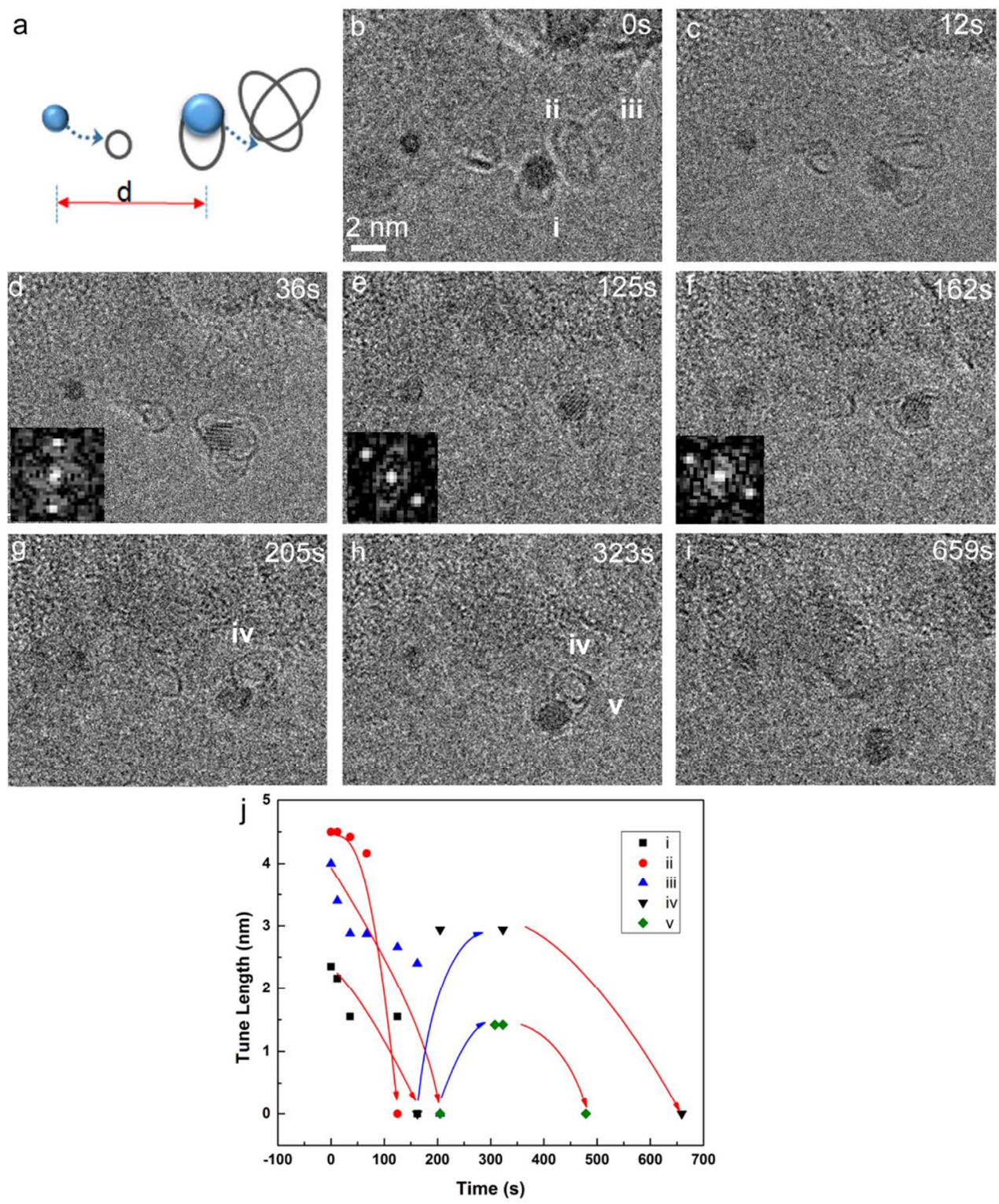

Figure 3. The termination and structural revolution of the SWCNTs grown at $700{ }^{\circ} \mathrm{C}$ in 7.6 mbar CO.

(a) Schematic of ejected weakly-attached fullerene/SWCNT from the particle, $\mathrm{d}$ is the distance between two particles. (b-i) A series of TEM images showing the "reversible" growth of SWCNTs. Multiple carbon structures settled close to the particles with matched sizes (panel b); Reactions between these 
carbon structures and the bigger particle in panels d-f, the FFTs inserted show the lattice fringes of the catalyst; Panels g-h show a new SWCNT and a peapod structure formed from the particle; The solid carbon structure was finally etched away (panel i). (j) Profiles of the length of SWCNTs/fullerenes vs. time.

Figure 3 shows the evidence of growth cessation of several short SWCNTs and their following interactions with the catalyst particle. The schematic and TEM image in Figures 3a-b represent a SWCNT (defined as tube i) tangentially connected to the high-contrast particle, with two detached SWCNTs (tube ii and tube iii) nearby and a fullerene close to another particle. Based on this tangential growth mode and their correlated sizes, we assume that the ejected carbon structures had been catalytically grown from the nearby particles, thus the two short tubes are the result of multiple nucleation from the same particle. This assumption has been confirmed by an in situ observation, that the tube $\mathrm{i}$ was abruptly ejected from the particle and settled down in a different direction at $12 \mathrm{~s}$ (Figure 3c), similar to the previous report. ${ }^{44}$ Remarkably, the possibility of electron beam (e-beam) damage effect on the termination process can be excluded, since the detachment of the tube ii and tube iii from the particles was observed at the region without previous e-beam illumination. Figures $3 c-j$ illustrate the subsequent evolutionary dynamics of these SWCNTs when in close contact with the particle. From 12 to $162 \mathrm{~s}$, the particle moved forward to "eat" the as-grown tubes gradually. During the process, a crystalline structure of the particle becomes visible. The measurements made from FFTs in Figures 3df shows that the lattice spacing of the catalyst particle is $2.48 \AA, 2.11 \AA$ and $2.18 \AA$, respectively. As argued above, they can be ascribed to several planes of $\mathrm{Co}_{2} \mathrm{C}$ or $\mathrm{Co}_{3} \mathrm{C}$. These carbide structures which fluctuate during CNT growth are similar to the in situ work by Yoshida. ${ }^{45}$ The lattice fringes of the same particle fade out as a new tube (tube iv) nucleated from it at $205 \mathrm{~s}$ (Figure $3 \mathrm{~g}$ ). Subsequently, 
another new nuclei (tube v) embedded in tube iv at $323 \mathrm{~s}$. They finally formed a peapod structure with tube $\mathrm{v}$ abruptly detaching itself from the particle (Figure 3h). The above observations show the partial decomposition of the original SWCNTs and the nucleation of new structures at the same nanoparticle. This also shows how the tube length varies over time in the profile in Figure 3j. The red arrow lines indicate the shortening of solid carbon frameworks, while the blue arrow lines indicate the process of new SWCNTs forming. This alternation process signifies a local carbon cycle assisted by the catalyst particle. The catalytic carbon gasification assisted by molecular etchants has been observed, ${ }^{46}$ but this is not the main reason for the disappearance of the tubes here, otherwise the process should not be "reversible" for the new growth run. Under the typical electron density of around (2 5) x10 e/nm", we have performed a blank experiment to study the e-beam effect (Figure S4 in Supporting Information). It has been found that there is little influence on the sample with an illumination of $\sim 1$ min, though slight damages were observed in $\sim 7 \mathrm{~min}$. Note that most of the reactions in this work occurred over a very short period of time, so we assume that the e-beam damage effect is negligible for most of the phenomena. Whereas, under a more intense e-beam illumination, we have indeed observed some severe damage on the carbon structures and the particle, accounting for why the newly formed tube appeared shorter and why there was no new carbon structure generated after $659 \mathrm{~s}$. The multiple and oscillating growth of SWCNTs from the same particle further confirms the long lifetime of catalysts and that the inadequate carbon supplies from low pressure $\mathrm{CO}$ is responsible for the discontinued growth of a long SWCNT. 

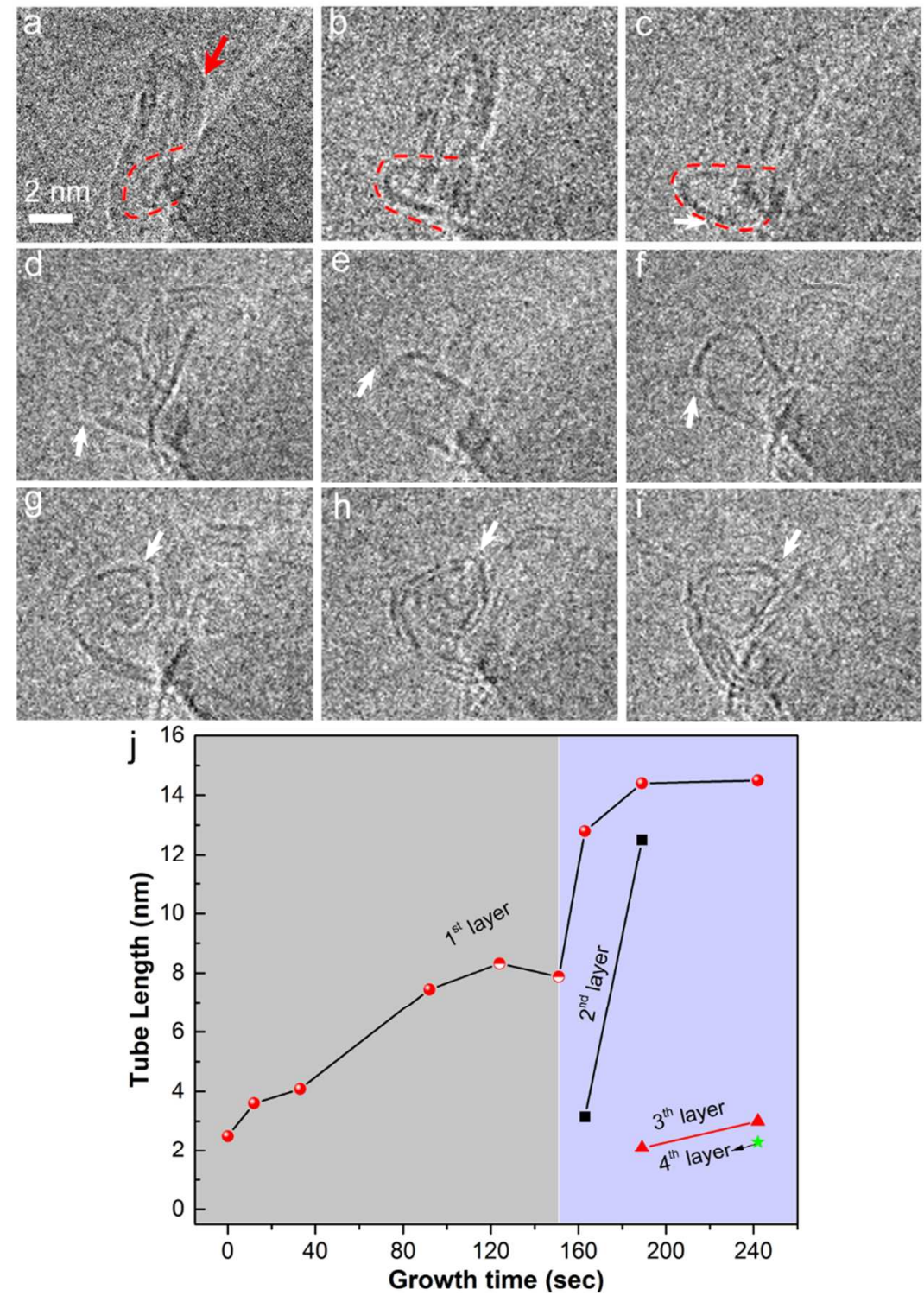

Figure 4. The growth and termination processes of a SWCNT and its evolution to a MWCNT. (a-f) Sequence of TEM images showing a defective SWCNT (marked by a dotted curve) elongated and broadened in diameter while consuming the initial-formed MWCNT (indicated by a red arrow) as solid carbon source. (g-i) Multiple tubes nucleated from the same particle. A kink in the SWCNT wall is indicated by a white arrow in panes c-i. (j) Growth kinetics of an initial SWCNT and its evolution to a MWCNT. 
Except for the nucleation of several discrete fullerenes/SWCNTs as shown above, Figure 4 shows a slightly different phenomenon of multiple nucleation of SWCNTs. An as-grown MWCNT (indicated by a red arrow) was found close to the catalyst particle with an identical diameter, which is very likely to be the initially product grown from the particle (Figure S5 in Supporting Information). Therefore, the dynamic growth process of the nanotube in Figure 4 is supposed to be the second nucleation from the same particle. As the newly formed SWCNT (marked by a dotted curve in Figures 4a-c) grew longer, the original MWCNT, with the sidewall partially contacting the particle, became smaller. This suggests that the formation of the new carbon structure is at the cost of this solid carbon, in agreement with the above phenomenon in Figure 3. Accompanied with that, the SWCNT continued growth and even after its cessation, new layers were able to nucleate from the same particle (Figure 4h). The white arrows in Figures 4c-i indicate a kink in the SWCNT wall, which might result from the deformation of the catalyst particle surface. ${ }^{47}$ Using the kink as a reference point, the length of the tube as a function of time was measured, as presented in the profile of Figure $4 \mathrm{j}$. Clearly, after the SWCNT growth cessation at around $150 \mathrm{~s}$, it can be further pushed forward by the growth of an inner layer until around $190 \mathrm{~s}$. Three additional SWCNT inner walls were formed sequentially from the same site of the particle (Figure 4i). This provides direct evidence of a "shell by shell" sequential nucleation process for a double-wall CNT (DWCNT), a triple-wall CNT and a MWCNT (see Figure S6 in Supporting Information). In addition, when following the growth of the initial SWCNT (Figures 4e-f), we see that its diameter broadened at the SWCNT-catalyst interface, to an even larger size than the particle. This intermediate state in the dynamical process, further reduced their circumferential contact area, namely, the SWCNT-catalyst adhesion strength, thus triggered the growth termination of the initial SWCNT. This gradual termination process is more moderate than the termination by necking down the interface, allowing for additional nucleation of inner walls. This enlargement of the tube diameter is one way to 
decrease the tube curvature energy and thereby the total energy level of the system. However, the exact reason for the changes, also on the catalyst-SWCNT adhesion strength, is still an open question. It may rely on tunable intermediate states of cobalt carbide, ${ }^{48}$ or be susceptive to growth conditions, here the active carbon supply. The active carbon atoms from the low-pressure gaseous carbon supplies and the involved solid carbon frameworks fluctuated during the tube growth, which might alter carbon chemical potential gradient (alter the driving force for the CNT growth) around a catalyst particle. ${ }^{47}$

\section{Growth termination of a long SWCNT}

The above observations suggest that in order to grow longer SWCNTs the pressure of the active carbon supply must be increased. However, the ETEM setup only allows a slight increase in CO pressure. Slightly longer SWCNTs $(<5 \mathrm{~nm})$ were then obtained compared to the fullerenes in Figure 1. In order to increase growth efficiency, we used $\mathrm{H}_{2}$ as an agent to assist the disproportionation or hydrogenation of $\mathrm{CO}^{50}$ based on the reactions of $2 \mathrm{CO}=\mathrm{C}+\mathrm{CO}_{2}$ and $\mathrm{CO}+\mathrm{H}_{2}=\mathrm{C}+\mathrm{H}_{2} \mathrm{O}$. A previous report shows, that the addition of $\mathrm{H}_{2}$ facilitates the synthesized carbon with quantitative analysis. ${ }^{51}$ When using a mixture of $\mathrm{CO} / \mathrm{H}_{2}$ at a ratio of $5: 2$, the amount of the produced carbon should be over 6 times higher than when using pure $\mathrm{CO}$, with Fe as catalysts. Here, under a total pressure of 7.4 mbar at 700 ${ }^{\circ} \mathrm{C}$ with a ratio $\mathrm{CO} / \mathrm{H}_{2}$ of $5: 2$, the SWCNT yield and growth rate were both improved compared to pure CO treatment (Figure S7 in Supporting Information). This indicates that either more active carbon atoms are provided at the growth front or carbon atoms are more efficiently incorporated into the tube (Table S1 in Supporting Information). Both are critical to the balance of a continued growth of SWCNTs. 

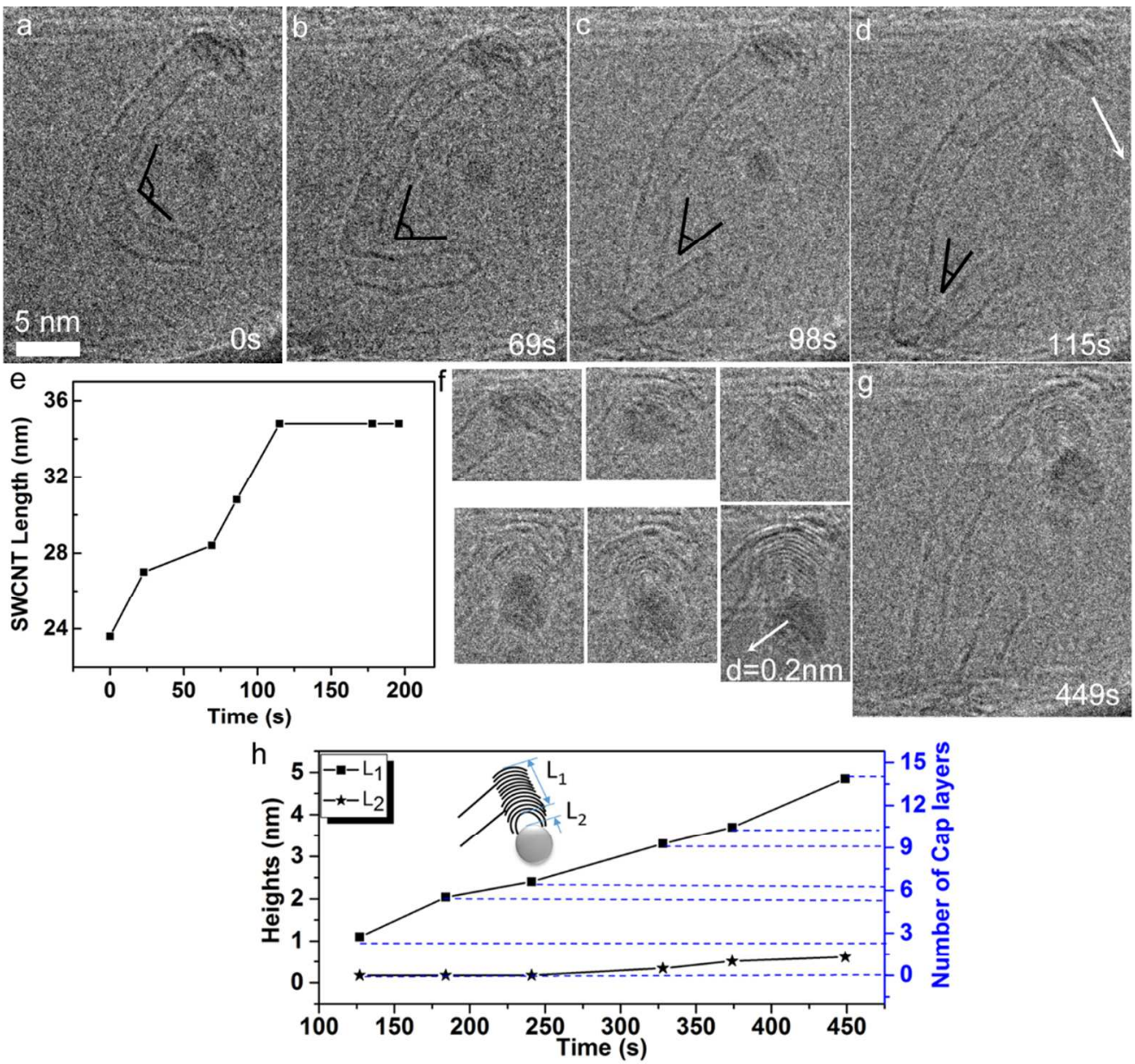

Figure 5. Growth and termination of a long SWCNT $(\sim 35 \mathrm{~nm})$ using a mixture of $\mathrm{CO} / \mathrm{H}_{2}(5: 2)$ as carbon sources. (a-d) A series of TEM images showing the growth of a SWCNT with the front segment bended during growth, the curved angle is marked. (e) Length of the SWCNT vs. growth time. (f-g) Multiple nucleation of caps (multi-layered graphene) from the same catalyst particle. (h) The related nucleation kinetics of the caps.

Figure 5 shows a time-sequence of TEM images extracted from Video S1 in Supporting Information, which represents the growth and its termination of a long SWCNT $(\sim 35 \mathrm{~nm})$. The average growth rate of this tube is about $0.1 \mathrm{~nm} / \mathrm{s}$, similar to the above observations when using pure $\mathrm{CO}$. The comparable growth rate indicates a similar incorporation rate of carbon atoms in the growth of a SWCNT $\left(\mathrm{C}_{\mathrm{inc}}{ }^{\prime}(\mathrm{t})\right)$, 
meaning that the supply rate of active carbon at the growth front $\left(\mathrm{C}_{\text {sup }}{ }^{\prime}(\mathrm{t})\right)$ was the limiting factor in the above experiment. This is in agreement with the previous report ${ }^{52}$ that too slow a carbon supply rate would form defect ridden tubes. We found from TEM images in Figures 5a-d that the diameter of the SWCNT is not constant (in the range of 1.7 to $2.8 \mathrm{~nm}$ ), indicating that the tube wall has a high defect density. Interestingly, the front segment of the SWCNT bended during growth, and the curved angle decreased distinctly when the kink hit the support (Figures 5c-d), implying that a certain amount of stresses, probably exerted from the underlying and nearby supports, was applied to the tube along its growth direction. As a result, the carbon incorporation process for the SWCNT growth fluctuated slightly, which might account for the formation of the defective tube. In fact, this compressive stress can be delivered to the tube-catalyst interface, as confirmed by the clearly deformed particle and the broadened tube diameter in Figure 5d. Consequently, at $115 \mathrm{~s}$, the SWCNT was totally blocked by the support and the growth halted with an abrupt stop in carbon incorporation $\left(C_{\text {inc }}(t)=0\right)$. Nevertheless, under this condition, the catalyst particle was still able to nucleate more than 10 graphene layers in the following $5 \mathrm{~min}$. The thickness of the stacking layers $\left(\mathrm{L}_{1}\right)$ is up to $5 \mathrm{~nm}$ (Figures $5 \mathrm{f}-\mathrm{h}$ ). Notably, the early stages of this hemisphere growth contain several graphene layers whose open edges are disconnected from the catalytic particle, which is different from the energy-favored configuration. ${ }^{37}$ Herein, we attribute the formation of this unfavorable configuration to the large driving force (chemical potential gradient around a catalyst particle) provided by the consecutive gaseous carbon supplies. ${ }^{49}$ When the number of layers reached $6 \sim 8$, the dangling bonds of the innermost cap starts to attach to the particle in order to decrease its energy. Meanwhile, the inner cap elongated into a tube $\left(\mathrm{L}_{2}\right)$ and finally ceased growing when the curvature of the innermost tube became too large to be favored in terms of energy. 
Based on the above evidence, the growth termination is attributed to the stresses exerted on the SWCNT or the SWCNT-catalyst interface, which broke the carbon equilibrium for SWCNT growth by suppressing the continuous incorporation of carbon atoms into the tube. Because the active carbon supply rate is much higher than for pure $\mathrm{CO}$, we thus assume it as a consecutive process, which makes excessive active carbon atoms $\left(\mathrm{C}_{\text {sup }}{ }^{\prime}(\mathrm{t})>\mathrm{C}_{\text {inc }}{ }^{\prime}(\mathrm{t})\right)$ available and finally leads to multiple nucleation of new caps. This conclusion can be confirmed by the fact that, rather than growing several SWCNTs from a stable particle (a root growth mode that SWCNTs mainly followed in this work), here the particle can be pushed forward by the multi-layer graphene. ${ }^{53}$ This complex structure is usually ascribed to nanotube poisoning at the growing end. ${ }^{17}$ This formation of the "dead" SWCNT is clearly different from the previous termination mechanism of MWCNTs, which was related to catalyst poisoning either by $\mathrm{H}_{2}$ modification ${ }^{52}$ or carbon encapsulation. ${ }^{19}$

\section{DISCUSSION}

By in situ TEM observations of the dynamical changes of nanostructures under several growth conditions, we have clarified the roles of catalysts and carbon sources on the growth termination of SWCNTs. The as-grown allotropes we have presented, such as fullerenes, peapods, MWCNTs, short and long SWCNTs, etc., can be regarded as the initial or evolved structures of SWCNTs. They are thereby appropriate examples, showing the long-lasting activity of catalysts regarding the multiple nucleation and SWCNT structural dependency on an active carbon supply. For instance, the formation of a fullerene can be regarded the cessation of an extreme short SWCNT (Figure 1). The sequentially formed peapod and MWCNT (Figures 3 and 4) result from the termination of the initial SWCNT and the multiple nucleation of new caps/SWCNTs from the same particle. The multi-layered graphene (Figure 5) is also the result of the multiple nucleation of caps from the same catalyst particle. Even 
though in situ TEM is a technique with limited statistics, we had at least three similar examples for each phenomenon to insure the validity of our results. It thus can be seen that, the formation of these various allotropes of SWCNTs all indicate some common causes for the SWCNT termination, even though they are following different termination paths as illustrated in the schematic of Figure 6.

As discussed above, both a non-steady supply of active carbon atoms (schematically shown as $\mathrm{C}_{2}$ dimers) limited by $\mathrm{CO}$ pressure and a suppression of carbon incorporation into the tube by stress exerted at the interface can be the reasons for a necking or broadening SWCNT-catalyst interface. In both cases, an imbalanced transport rate of carbon $\left(\mathrm{C}_{\text {sup }}{ }^{\prime}(\mathrm{t}) \neq \mathrm{C}_{\text {inc }}(\mathrm{t})\right)$ through/over catalyst particles reduced the catalyst-SWCNT bond strength and finally ceased the SWCNT growth. In the former case, the SWCNTs that abruptly terminated growing can further detach from the particle or rotate around it (Figure S6 in Supporting Information). With continuous carbon supplies, several fullerenes, SWCNTs, or peapod structures nucleate from the same particle. In the latter case, the SWCNT with its broadened diameter is only weakly connected to the particle, and can gradually form a "dead" SWCNT or a DWCNT (only double growth is illustrated) when incorporating more active carbon atoms. Note that in this study, both of the tube detachment and multiple nucleation of tubes can be the subsequent results of the weakened tube-catalyst interfaces, hence signifying the growth termination.

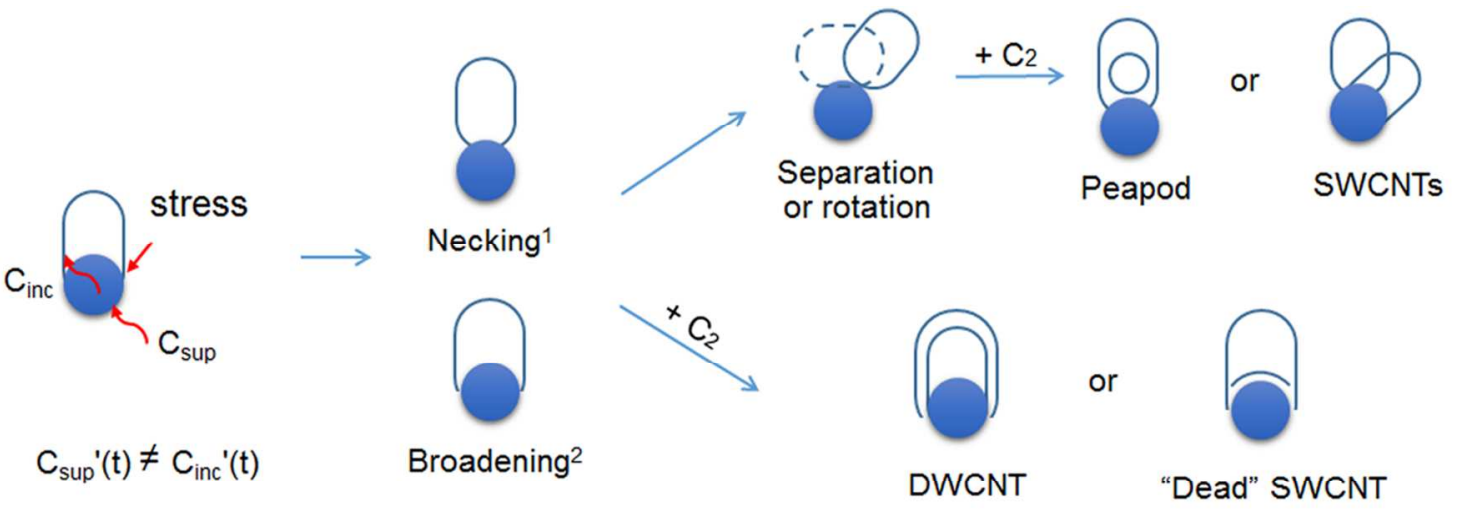

1. $C_{\text {sup }}{ }^{\prime}(t)<C_{\text {inc }}{ }^{\prime}(t) ; 2 . C_{\text {sup }}^{\prime}(t)>C_{\text {inc }}{ }^{\prime}(t)$ 
Figure 6. Growth termination of an individual SWCNT and its possible evolutions without and with additional carbon supplies. In the former case, SWCNT growth halted with a necking tube-catalyst interface, when active carbon supply rate $\left(\mathrm{C}_{\text {sup }}{ }^{\prime}(\mathrm{t})\right)$ decreased or carbon incorporation rate $\left(\mathrm{C}_{\text {inc }}(\mathrm{t})\right)$ increased abruptly. On the contrary, SWCNT growth was hindered in the way of forming a broadening interface. In both cases, the terminated tubes are weakly connected to the particle and can evolve to different structures.

As we are mainly investigating well separated individual particles, the influence of a change in gas diffusion through a CNT carpet $^{52}$ can be excluded. Meanwhile, because it is impossible to clarify all the possible factors in one work, the deactivation of catalysts by carbon encapsulation thereby cannot be totally ruled out, even though it is rarely experimentally observed in this work. This study suggests us that the equilibrium of the transport rate of carbon $\left(\mathrm{C}_{\text {sup }}{ }^{\prime}(\mathrm{t}) \rightleftarrows \mathrm{C}_{\text {inc }}{ }^{\prime}(\mathrm{t})\right)$ through/over catalyst particles is the key for continued growth, with catalyst particles remaining active at all times. As stated above, active carbon atoms were supplied to the growth front. This process includes adsorption and dissociation of carbon precursors on the catalyst surface and transport of the active carbon atoms to the growth front. While the process of consecutively incorporating carbon atoms means the transport of active carbon atoms to assemble SWCNT structures. Experimentally, different carbon transport processes have been discussed for SWCNT growth, such as bulk diffusion through particles, ${ }^{38} 45$ surface diffusion ${ }^{55-56}$ and subsurface diffusion ${ }^{57}$ over particles. Our observations show, that both solid carbide and droplet-like particles catalyze the nucleation of fullerenes or SWCNTs, indicating that some of the cases co-exist. For the growth of SWCNTs, carbon diffusion through the bulk or subsurface of particles might be the dominating diffusion paths. Nevertheless, we see less sensitivity of the growth rate to temperature (in the range of 650 to $900{ }^{\circ} \mathrm{C}$ ) when using $\mathrm{CO}$ and comparable growth 
rates for $\mathrm{CO}$ and $\mathrm{CO}+\mathrm{H}_{2}$, indicating that the exact diffusion process, however, is not the limiting factor. Instead, the creation of atomic carbon has a stronger influence on the growth rate, in line with the literature. ${ }^{38}$ Even though we have not discussed the carbon solubility ${ }^{58}$ or the composition ${ }^{59}$ of catalysts as impact factors for the continued growth of SWCNTs in this work, their functions, combined with growth conditions, should be considered in relation to the growth termination of a SWCNT, especially when carbon source is sufficiently supplied. It was calculated that it is energetically favorable for SWCNTs synthesized from noble metal catalysts to close their open ends. ${ }^{31}$ However, recent experimental work have demonstrated that $\mathrm{Cu}^{60} \mathrm{Au}^{61}$ and $\mathrm{Pt}^{62}$ catalyst particles are able to grow SWCNTs efficiently under proper growth conditions. As carbon solubility is much lower, the transport process of carbon atoms to the growth front might be a rate-limiting step, different from metals like Co or Ni. Therefore, the parameters that influence this step, such as the choice of growth temperature, ${ }^{63-64}$ catalyst composition $^{3,65}$ or size, ${ }^{61,65}$ should also be considered. These may contribute to the reaction equilibrium $\left(\mathrm{C}_{\text {sup }}{ }^{\prime}(\mathrm{t}) \rightleftarrows \mathrm{C}_{\text {inc }}{ }^{\prime}(\mathrm{t})\right)$ for the continuous growth or structure controlling of SWCNTs. The SWCNT growth termination studies with noble metal catalysts following this work are in progress.

When the above equilibrium is broken, we see from the schematic in Figure 6 that SWCNTs cease growing or evolve into new structures. We have also demonstrated at nanoscale that with insufficient or non-steady active carbon supply, the initial SWCNTs contact with catalyst particles can be etched, resulting in the following equilibrium ( $\mathrm{M}$ being the metal catalyst).

$$
\mathrm{C} \cdot(\mathrm{g})+\mathrm{C}_{(\mathrm{s})} \stackrel{M}{\Leftrightarrow} \mathrm{SWCNTs}
$$

The "reversible" growth processes in Figure 3 suggest that the growth of CNTs is a dynamic balance between providing active carbon atoms at the growth front and incorporating solid carbon in the growing tube within a certain time frame. It agrees with the report ${ }^{66}$ that SWCNT growth is a 
competitive process between a tube elongation and a tube etching by catalysts. This means the accumulation rate of active carbon atoms at the growth front $\left(\mathrm{C}_{\text {sup }}{ }^{\prime}(\mathrm{t})\right)$ should be equal to the SWCNT growth rate $\left(\mathrm{C}_{\mathrm{inc}}{ }^{\prime}(\mathrm{t})\right)$. This active carbon consists of both gaseous and solid carbon $\left(\mathrm{C}^{\cdot}(\mathrm{g})\right.$ and $\left.\mathrm{C}_{(\mathrm{s})}\right)$. Only when gaseous carbon supplies are insufficient and solid carbon sources are in direct contact with particles, do they compensate for the reaction. Here we are able to observe the etching process of asgrown CNTs, due to the low activation energy in the CNT synthesis stemming from the disproportionation of CO. ${ }^{38,54}$ With higher growth rates of SWCNTs (Figures 2-4) than carbon supply rates, or a resistance to incorporate carbon atoms (Figure 5) at the latter growth stage, the growth stops due to the broken carbon equilibrium. Additional solid carbon sources, like as-grown tubes, are able to be involved in the above reaction for an additional growth of SWCNTs (Figures 3 and 4). From this point, we can see the importance of the carbon cycle on the quality or uniformity of CNT structures.

Generally, this growth termination strongly relies on the balance in a carbon cycle through or on particles. Namely, factors or conditions distorting the equilibrium, such as changes of carbon supplies, ${ }^{24,27,67}$ structural evolution (or phase changes) of catalysts, ${ }^{28}$ exertion of internal $^{68}$ or external $^{69}$ forces, etc., which can induce growth termination. The key factors accounting for the limited growth may be different when using different catalysts and carbon-containing precursors. From this conclusion, we can predict, that defective tubes with amorphous carbon adsorbed or kinks formed on the wall, rarely form too long structures, because the internal stresses produced on the wall might disrupt the equilibrium and hinder the elongation of SWCNTs. This agrees well with some of the known phenomena, such as that long CNTs are only produced with aligned orientation and high quality, ${ }^{70-72}$ and that randomly oriented SWCNTs are statistically much shorter than the aligned SWCNTs, ${ }^{73}$ etc. By a combination of limited carbon supply in the late growth stage of CNTs, due to geometrical limitations, and stresses of structural disorders, ${ }^{24}$ the CNT growth in vertically aligned 
arrays follows an exponential decay growth model. ${ }^{23,27}$ It suggests that the termination mechanism proposed in this study might be extended into high pressure regimes, even though it was performed at low pressure. We can also take advantage of the termination mechanism to control the growth kinetics of SWCNTs. For instance, a suitable force and growth window is needed to adjust the CNT length by artificially designing a crossing tube as a barrier, ${ }^{68}$ or to engineer the morphology of CNT arrays by applying external forces. ${ }^{74}$ With an accurate measurement or control of the exerted forces in the future, the relationship between the force and SWCNTs with a specific structure might be further clarified.

\section{CONCLUSION}

In summary, we have investigated in real time the growth kinetics and termination of SWCNTs by $\mathrm{Co} / \mathrm{MgO}$ catalysts. From the above evidences, we present that SWCNTs cease growing in two ways: necking or broadening the tube-catalyst interface. The sequential nucleation processes from the same particle produce new structures such as fullerenes, peapods, and MWCNTs, suggesting the long-lasting activity of catalysts. While replacing a pure $\mathrm{CO}$ precursor with a mixture of $\mathrm{CO}$ and $\mathrm{H}_{2}$, the growth of a longer tube and its cessation by stresses exerted on the tube-catalyst interface were observed. Therefore, it is proposed that the possible reasons for the discontinued growth of SWCNTs might be the broken carbon cycle through or over catalyst particles. Though for a different catalytic system or condition, there may exist some other factors disrupting the SWCNT growth, e.g., factors influencing the features of catalysts. Special attention should be paid to the stability of carbon supplies and the growth environments in the future studies. This termination mechanism lends support to many phenomena of CNT growth and provides great insights which enables further control over the structure of SWCNTs individually or on a macroscale.

\section{MATERIALS AND METHODS}


The $\mathrm{Co} / \mathrm{MgO}$ catalysts were prepared by the impregnation method ${ }^{75}$ with Cobalt (III) acetylacetonate (98\%, Aldrich) solution, followed by a calcination at $800{ }^{\circ} \mathrm{C}$ for $20 \mathrm{~h}$, the loading of Co is $\sim 7 \%$ in mole ratio. The sample was dispersed in ethanol and drop-casted on a MEMS-based micro-heater from DENSsolutions. After drying at room temperature, the sample was investigated in an ETEM (FEI Titan 80-300ST) operated at $300 \mathrm{kV}$. CO was let into the microscope, building up a pressure of 1.6 mbar under constant flow. In order to form distinct Co particles on the $\mathrm{MgO}$ support, the sample was heated to $300{ }^{\circ} \mathrm{C}$. After that, the pressure of $\mathrm{CO}$ was increased to 5.3-7.6 mbar and the temperature was increased up to the target growth temperature of $700{ }^{\circ} \mathrm{C}$. As a comparison, we used the same catalyst system to grow SWCNTs with a mixture of $\mathrm{CO}$ and $\mathrm{H}_{2}$. The specimen was heated to $700{ }^{\circ} \mathrm{C}$ and reduced under $\mathrm{H}_{2}$ (2 mbar) for $1 \mathrm{~h}$, then a flow of $\mathrm{CO}$ and $\mathrm{H}_{2}$ (5:2 in volumetric ratio) at a total pressure of 7.4 mbar was introduced into the TEM chamber for CNT growth. During the above processes, the kinetics of particles and SWCNTs were observed and recorded on a Gatan US1000 camera with an exposure time of $0.5 \mathrm{~s}$. Their structural characterization was performed during or after growth.

\section{ASSOCIATED CONTENT}

Supporting Information Available: Figures showing the formation of catalyst particles on $\mathrm{MgO}$ support; beam effect on the dissociation of a SWCNT from a catalyst particle; multiple nucleation of SWCNTs with $\mathrm{CO}$; the growth products from a mixture $\mathrm{CO}$ and $\mathrm{H}_{2}$. A video representing the growth kinetics of a long SWCNT using a mixture $\mathrm{CO}$ and $\mathrm{H}_{2}$ as carbon sources. This material is available free of charge via the Internet at http://pubs.acs.org.

\section{AUTHOR INFORMATION}

\section{Corresponding Authors}


*E-mail: lilizha@dtu.dk.

*E-mail: jakob.wagner@cen.dtu.dk.

\section{Author Contributions}

The manuscript was written through contributions of all authors. All authors have given approval to the final version of the manuscript.

\section{ACKNOWLEDGMENT}

The research leading to these results has received funding from the European Union Seventh Framework Programme (FP7/2007-2013) under grant agreement nº 604472 (IRENA). M. He would also like to acknowledge Scientific Research Foundation of Shandong University of Science and Technology for Recruited Talents (No. 2016RCJJ001). The authors would like to acknowledge I. B. Møller for help with language editing. This publication reflects only the author's views. The European Union is not liable for any use that may be made of the information contained herein.

\footnotetext{
ABBREVIATIONS

SWCNTs, single-wall carbon nanotubes; TEM, transmission electron microscopy; ETEM, environmental TEM; MWCNTs, multi-wall CNTs; DWCNT, double-wall CNT; ${ }^{\cdot}{ }_{(\mathrm{g})}$ and $\mathrm{C}_{(\mathrm{s})}$, gaseous and solid carbon; $\mathrm{C}_{\text {sup }}{ }^{\prime}(\mathrm{t})$, active carbon supply rate; $\mathrm{C}_{\mathrm{inc}}{ }^{\prime}(\mathrm{t})$, $\mathrm{SWCNT}$ growth (carbon incorporation) rate.
}

REFERENCES 
1. Chen, Y.; Zhang, J. Chemical Vapor Deposition Growth of Single-Walled Carbon Nanotubes with Controlled Structures for Nanodevice Applications. Acc. Chem. Res. 2014, 47, 2273-2281.

2. Li, Y.; Cui, R.; Ding, L.; Liu, Y.; Zhou, W.; Zhang, Y.; Jin, Z.; Peng, F.; Liu, J. How Catalysts Affect the Growth of Single-Walled Carbon Nanotubes on Substrates. Adv. Mater. 2010, 22, 15081515.

3. Yang, F.; Wang, X.; Zhang, D.; Yang, J.; LuoDa; Xu, Z.; Wei, J.; Wang, J. Q.; Xu, Z.; Peng, F. et al. Chirality-Specific Growth of Single-Walled Carbon Nanotubes on Solid Alloy Catalysts. Nature 2014, 510, 522-524.

4. Picher, M.; Anglaret, E.; Arenal, R.; Jourdain, V. Processes Controlling the Diameter Distribution of Single-Walled Carbon Nanotubes during Catalytic Chemical Vapor Deposition. ACS Nano 2011, $5,2118-2125$.

5. Reich, S.; Li, L.; Robertson, J. Epitaxial Growth of Carbon Caps on Ni for Chiral Selectivity. Phys. Status Solidi B 2006, 243, 3494-3499.

6. Zhang, Y.; Li, Y.; Kim, W.; Wang, D.; Dai, H. Imaging As-grown Single-Walled Carbon Nanotubes Originated from Isolated Catalytic Nanoparticles. Appl. Phys. A: Mater. Sci. Process. 2002, 74, 325-328.

7. Fiawoo, M. F. C.; Bonnot, A. M.; Amara, H.; Bichara, C.; Thibault-Pénisson, J.; Loiseau, A. Evidence of Correlation between Catalyst Particles and the Single-Wall Carbon Nanotube Diameter: A First Step towards Chirality Control. Phys. Rev. Lett. 2012, 108, 195503.

8. Zhu, H.; Suenaga, K.; Hashimoto, A.; Urita, K.; Hata, K.; Iijima, S. Atomic-Resolution Imaging of the Nucleation Points of Single-Walled Carbon Nanotubes. Small 2005, 1, 1180-1183.

9. Helveg, S.; Lopez-Cartes, C.; Sehested, J.; Hansen, P. L.; Clausen, B. S.; Rostrup-Nielsen, J. R.; Abild-Pedersen, F.; Norskov, J. K. Atomic-Scale Imaging of Carbon Nanofibre Growth. Nature 2004, 427, 426-429.

10. Rao, R.; Sharma, R.; Abild-Pedersen, F.; Norskov, J. K.; Harutyunyan, A. R. Insights Into Carbon Nanotube Nucleation: Cap Formation Governed by Catalyst Interfacial Step Flow. Sci. Rep. 2014, 4.

11. Picher, M.; Lin, P. A.; Gomez-Ballesteros, J. L.; Balbuena, P. B.; Sharma, R. Nucleation of Graphene and Its Conversion to Single-Walled Carbon Nanotubes. Nano Lett. 2014, 14, 6104-6108.

12. Thess, A.; Lee, R.; Nikolaev, P.; Dai, H. J.; Petit, P.; Robert, J.; Xu, C. H.; Lee, Y. H.; Kim, S. G.; Rinzler, A. G. et al. Crystalline Ropes of Metallic Carbon Nanotubes. Science 1996, 273, 483-487.

13. Wang, Q.; Ng, M. F.; Yang, S. W.; Yang, Y. H.; Chen, Y. A. The Mechanism of Single-Walled Carbon Nanotube Growth and Chirality Selection Induced by Carbon Atom and Dimer Addition. ACS Nano 2010, 4, 939-946.

14. Yao, Y.; Li, Q.; Zhang, J.; Liu, R.; Jiao, L.; Zhu, Y. T.; Liu, Z. Temperature-Mediated Growth of Single-Walled Carbon-Nanotube Intramolecular Junctions. Nat. Mater. 2007, 6, 283-286.

15. Romo-Herrera, J. M.; Cullen, D. A.; Cruz-Silva, E.; Ramírez, D.; Sumpter, B. G.; Meunier, V.; Terrones, H.; Smith, D. J.; Terrones, M. The Role of Sulfur in the Synthesis of Novel Carbon Morphologies: From Covalent Y-Junctions to Sea-Urchin-Like Structures. Adv. Funct. Mater. 2009, 19, 1193-1199.

16. Nessim, G. D.; Hart, A. J.; Kim, J. S.; Acquaviva, D.; Oh, J.; Morgan, C. D.; Seita, M.; Leib, J. S.; Thompson, C. V. Tuning of Vertically-Aligned Carbon Nanotube Diameter and Areal Density Through Catalyst Pre-treatment. Nano Lett. 2008, 8, 3587-3593.

17. Stadermann, M.; Sherlock, S. P.; In, J. B.; Fornasiero, F.; Park, H. G.; Artyukhin, A. B.; Wang, Y. M.; De Yoreo, J. J.; Grigoropoulos, C. P.; Bakajin, O. et al. Mechanism and Kinetics of Growth 
Termination in Controlled Chemical Vapor Deposition Growth of Multiwall Carbon Nanotube Arrays. Nano Lett. 2009, 9, 738-744.

18. Geohegan, D. B.; Puretzky, A. A.; Jackson, J. J.; Rouleau, C. M.; Eres, G.; More, K. L. FluxDependent Growth Kinetics and Diameter Selectivity in Single-Wall Carbon Nanotube Arrays. ACS Nano 2011, 5, 8311-8321.

19. Reilly, P. T. A.; Whitten, W. B. The Role of Free Radical Condensates in the Production of Carbon Nanotubes during the Hydrocarbon CVD Process. Carbon 2006, 44, 1653-1660.

20. Hata, K.; Futaba, D. N.; Mizuno, K.; Namai, T.; Yumura, M.; Iijima, S. Water-Assisted Highly Efficient Synthesis of Impurity-Free Single-Walled Carbon Nanotubes. Science 2004, 306, 13621364.

21. Zhang, G.; Mann, D.; Zhang, L.; Javey, A.; Li, Y.; Yenilmez, E.; Wang, Q.; McVittie, J. P.; Nishi, Y.; Gibbons, J.; Dai, H. Ultra-High-Yield Growth of Vertical Single-Walled Carbon Nanotubes: Hidden Roles of Hydrogen and Oxygen. Proc. Natl. Acad. Sci. 2005, 102, 16141-16145.

22. Amama, P. B.; Pint, C. L.; McJilton, L.; Kim, S. M.; Stach, E. A.; Murray, P. T.; Hauge, R. H.; Maruyama, B. Role of Water in Super Growth of Single-Walled Carbon Nanotube Carpets. Nano Lett. 2009, 9, 44-49.

23. Futaba, D. N.; Hata, K.; Yamada, T.; Mizuno, K.; Yumura, M.; Iijima, S. Kinetics of WaterAssisted Single-Walled Carbon Nanotube Synthesis Revealed by a Time-Evolution Analysis. Phys. Rev. Lett. 2005, 95, 056104.

24. Meshot, E. R.; Hart, A. J., Abrupt Self-Termination of Vertically Aligned Carbon Nanotube Growth. Appl. Phys. Lett. 2008, 92, 113107.

25. Maruyama, S.; Einarsson, E.; Murakami, Y.; Edamura, T. Growth Process of Vertically Aligned Single-Walled Carbon Nanotubes. Chem. Phys. Lett. 2005, 403, 320-323.

26. Xiang, R.; Yang, Z.; Zhang, Q.; Luo, G.; Qian, W.; Wei, F.; Kadowaki, M.; Einarsson, E.; Maruyama, S. Growth Deceleration of Vertically Aligned Carbon Nanotube Arrays: Catalyst Deactivation or Feedstock Diffusion Controlled? J. Phys. Chem. C 2008, 112, 4892-4896.

27. Picher, M.; Anglaret, E.; Arenal, R.; Jourdain, V. Self-Deactivation of Single-Walled Carbon Nanotube Growth Studied by In Situ Raman Measurements. Nano Lett. 2009, 9, 542-547.

28. Kim, S. M.; Pint, C. L.; Amama, P. B.; Zakharov, D. N.; Hauge, R. H.; Maruyama, B.; Stach, E. A. Evolution in Catalyst Morphology Leads to Carbon Nanotube Growth Termination. J. Phys. Chem. Lett. 2010, 1, 918-922.

29. Gamalski, A.; Moore, E. S.; Treacy, M. M. J.; Sharma, R.; Rez, P. Diffusion-Gradient-Induced Length Instabilities in the Catalytic Growth of Carbon Nanotubes. Appl. Phys. Lett. 2009, 95, 233109.

30. Hansen, T. W.; Wagner, J. B.; Dunin-Borkowski, R. E. Aberration Corrected and Monochromated Environmental Transmission Electron Microscopy: Challenges and Prospects for Materials Science. Mater. Sci. Technol. 2010, 26, 1338-1344.

31. Ding, F.; Larsson, P.; Larsson, J. A.; Ahuja, R.; Duan, H.; Rosén, A.; Bolton, K. The Importance of Strong Carbon-Metal Adhesion for Catalytic Nucleation of Single-Walled Carbon Nanotubes. Nano Lett. 2007, 8, 463-468.

32. Nasibulin, A. G.; Pikhitsa, P. V.; Jiang, H.; Brown, D. P.; Krasheninnikov, A. V.; Anisimov, A. S.; Queipo, P.; Moisala, A.; Gonzalez, D.; Lientschnig, G. et al. A Novel Hybrid Carbon Material. Nat. Nanotechnol. 2007, 2, 156-161.

33. Chow, L.; Wang, H.; Kleckley, S.; Daly, T. K.; Buseck, P. R. Fullerene formation during production of chemical vapor deposited diamond. Appl. Phys. Lett. 1995, 66, 430-432. 
34. Cheng, H. M.; Li, F.; Su, G.; Pan, H. Y.; He, L. L.; Sun, X.; Dresselhaus, M. S. Large-Scale and Low-Cost Synthesis of Single-Walled Carbon Nanotubes by the Catalytic Pyrolysis of Hydrocarbons. Appl. Phys. Lett. 1998, 72, 3282-3284.

35. Ren, W. C.; Li, F.; Bai, S.; Cheng, H. M. The Effect of Sulfur on the Structure of Carbon Nanotubes Produced by a Floating Catalyst Method. J. Nanosci. Nanotechnol. 2006, 6, 1339-1345.

36. Zhang, L.; Hou, P. X.; Li, S.; Shi, C.; Cong, H. T.; Liu, C.; Cheng, H. M. In Situ TEM Observations on the Sulfur-Assisted Catalytic Growth of Single-Wall Carbon Nanotubes. J. Phys. Chem. Lett. 2014, 5, 1427-1432.

37. Dai, H.; Rinzler, A. G.; Nikolaev, P.; Thess, A.; Colbert, D. T.; Smalley, R. E. Single-Wall Nanotubes Produced by Metal-Catalyzed Disproportionation of Carbon Monoxide. Chem. Phys. Lett. 1996, 260, 471-475.

38. Hafner, J. H.; Bronikowski, M. J.; Azamian, B. R.; Nikolaev, P.; Rinzler, A. G.; Colbert, D. T.; Smith, K. A.; Smalley, R. E. Catalytic Growth of Single-Wall Carbon Nanotubes from Metal Particles. Chem. Phys. Lett. 1998, 296, 195-202.

39. He, M.; Jiang, H.; Kauppi, I.; Fedotov, P. V.; Chernov, A. I.; Obraztsova, E. D.; Cavalca, F.; Wagner, J. B.; Hansen, T.; Sainio, J. et al. Insights into Chirality Distributions of Single-Walled Carbon Nanotube Grown on Different $\mathrm{Co}_{\mathrm{x}} \mathrm{Mg}_{1-\mathrm{x}} \mathrm{O}$ Solid Solutions. J. Mater. Chem. A 2014, 2, 5883-5889.

40. Bronikowski, M. J.; Willis, P. A.; Colbert, D. T.; Smith, K. A.; Smalley, R. E. Gas-Phase Production of Carbon Single-Walled Nanotubes from Carbon Monoxide via the HiPco Process: A Parametric Study. J.Vac. Sci. Technol., A 2001, 19, 1800-1805.

41. Chen, Y.; Ciuparu, D.; Lim, S.; Yang, Y.; Haller, G. L.; Pfefferle, L. Synthesis of Uniform Diameter Single Wall Carbon Nanotubes in Co-MCM-41: Effects of CO Pressure and Reaction Time. J. Catal. 2004, 226, 351-362.

42. Wang, B.; Wei, L.; Yao, L.; Li, L. J.; Yang, Y.; Chen, Y. Pressure-Induced Single-Walled Carbon Nanotube (n,m) Selectivity on Co-Mo Catalysts. J. Phys. Chem. C 2007, 111, 14612-14616.

43. Burgos, J. C.; Jones, E.; Balbuena, P. B. Dynamics of Topological Defects in Single-Walled Carbon Nanotubes during Catalytic Growth. J. Phys. Chem. C 2014, 118, 4808-4817.

44. Zhang, L.; Hou, P. X.; Li, S.; Shi, C.; Cong, H. T.; Liu, C.; Cheng, H. M. In Situ TEM Observations on the Sulfur-Assisted Catalytic Growth of Single-Wall Carbon Nanotubes. J. Phys. Chem. Lett. 2014, 5, 1427-1432.

45. Yoshida, H.; Takeda, S.; Uchiyama, T.; Kohno, H.; Homma, Y. Atomic-Scale In-situ Observation of Carbon Nanotube Growth from Solid State Iron Carbide Nanoparticles. Nano Lett. 2008, 8, 2082-2086.

46. Feng, X.; Chee, S.; Sharma, R.; Liu, K.; Xie, X.; Li, Q.; Fan, S.; Jiang, K. In Situ TEM Observation of the Gasification and Growth of Carbon Nanotubes using Iron Catalysts. Nano Res. 2011, 1-13.

47. Yoshida, H.; Takeda, S. Elucidation of the Origin of Grown-in Defects in Carbon Nanotubes. Carbon 2014, 70, 266-272.

48. Wirth, C. T.; Hofmann, S.; Robertson, J. State of the Catalyst during Carbon Nanotube Growth. Diamond Relat. Mater. 2009, 18, 940-945.

49. Amara, H.; Bichara, C.; Ducastelle, F. Understanding the Nucleation Mechanisms of Carbon Nanotubes in Catalytic Chemical Vapor Deposition. Phys. Rev. Lett. 2008, 100, 056105.

50. Zheng, B.; Lu, C.; Gu, G.; Makarovski, A.; Finkelstein, G.; Liu, J. Efficient CVD Growth of Single-Walled Carbon Nanotubes on Surfaces Using Carbon Monoxide Precursor. Nano Lett. 2002, 2, 895-898. 
51. Chung, U. C. Effect of $\mathrm{H}_{2}$ on Formation Behavior of Carbon Nanotubes. Bull. Korean Chem. Soc. 2004, 25, 1521-1524.

52. Mora, E.; Harutyunyan, A. R. Study of Single-Walled Carbon Nanotubes Growth via the Catalyst Lifetime. J. Phys. Chem. C 2008, 112, 4805-4812.

53. Merkulov, V. I.; Melechko, A. V.; Guillorn, M. A.; Lowndes, D. H.; Simpson, M. L. Alignment Mechanism of Carbon Nanofibers Produced by Plasma-Enhanced Chemical-Vapor Deposition. Appl. Phys. Lett. 2001, 79, 2970-2972.

54. In, J. B.; Grigoropoulos, C. P.; Chernov, A. A.; Noy, A. Growth Kinetics of Vertically Aligned Carbon Nanotube Arrays in Clean Oxygen-free Conditions. ACS Nano 2011, 5, 9602-9610.

55. Takagi, D.; Kobayashi, Y.; Hommam, Y. Carbon Nanotube Growth from Diamond. J. Am. Chem. Soc. 2009, 131, 6922-6923.

56. Liu, B.; Tang, D. M.; Sun, C.; Liu, C.; Ren, W.; Li, F.; Yu, W. J.; Yin, L. C.; Zhang, L.; Jiang, C. et al. Importance of Oxygen in the Metal-Free Catalytic Growth of Single-Walled Carbon Nanotubes from $\mathrm{SiO}_{\mathrm{x}}$ by a Vapor-Solid-Solid Mechanism. J. Am. Chem. Soc. 2010, 133, 197-199.

57. Sakurai, S.; Nishino, H.; Futaba, D. N.; Yasuda, S.; Yamada, T.; Maigne, A.; Matsuo, Y.; Nakamura, E.; Yumura, M.; Hata, K. Role of Subsurface Diffusion and Ostwald Ripening in Catalyst Formation for Single-Walled Carbon Nanotube Forest Growth. J. Am. Chem. Soc. 2011, $134,2148-2153$.

58. He, M.; Amara, H.; Jiang, H.; Hassinen, J.; Bichara, C.; Ras, R. H. A.; Lehtonen, J.; Kauppinen, E. I.; Loiseau, A. Key Roles of Carbon Solubility in Single-Walled Carbon Nanotube Nucleation and Growth. Nanoscale 2015, 7, 20284-20289.

59. Crouse, C. A.; Maruyama, B.; Colorado Jr, R.; Back, T.; Barron, A. R. Growth, New Growth, and Amplification of Carbon Nanotubes As a Function of Catalyst Composition. J. Am. Chem. Soc. 2008, 130, 7946-7954.

60. Weiwei, Z.; Zuoyan, H.; Jinyong, W.; Yan, Z.; Zhong, J.; Xiao, S.; Yawen, Z.; Chunhua, Y.; Yan, L. Copper Catalyzing Growth of Single-Walled Carbon Nanotubes on Substrates. Nano Lett. 2006, 6, 2987-2990.

61. Bhaviripudi, S.; Mile, E.; Steiner, S. A.; Zare, A. T.; Dresselhaus, M. S.; Belcher, A. M.; Kong, J. CVD Synthesis of Single-Walled Carbon Nanotubes from Gold Nanoparticle Catalysts. J. Am. Chem. Soc. 2007, 129, 1516-1517.

62. Maruyama, T.; Kondo, H.; Ghosh, R.; Kozawa, A.; Naritsuka, S.; Iizumi, Y.; Okazaki, T.; Iijima, S. Single-Walled Carbon Nanotube Synthesis using Pt Catalysts under Low Ethanol Pressure via Cold-Wall Chemical Vapor Deposition in High Vacuum. Carbon 2016, 96, 6-13.

63. Tang, C.; Guo, W.; Chen, C. Mechanism for Superelongation of Carbon Nanotubes at High Temperatures. Phys. Rev. Lett. 2008, 100, 175501.

64. Mora, E.; Pigos, J. M.; Ding, F.; Yakobson, B. I.; Harutyunyan, A. R. Low-Temperature SingleWall Carbon Nanotubes Synthesis: Feedstock Decomposition Limited Growth. J. Am. Chem. Soc. 2008, 130, 11840-11841.

65. Chiang, W. H.; Sankaran, R. M. Relating Carbon Nanotube Growth Parameters to the Size and Composition of Nanocatalysts. Diamond Relat. Mater. 2009, 18, 946-952.

66. Orbaek, A. W.; Owens, A. C.; Barron, A. R. Increasing the Efficiency of Single Walled Carbon Nanotube Amplification by Fe-Co Catalysts Through the Optimization of $\mathrm{CH}_{4} / \mathrm{H}_{2}$ Partial Pressures. Nano Lett. 2011, 11, 2871-2874.

67. lijima, S.; Ichihashi, T.; Ando, Y. Pentagons, Heptagons and Negative Curvature in Graphite Microtubule Growth. Nature 1992, 356, 776-778. 
68. Feng, C. Q.; Yao, Y. G.; Zhang, J.; Liu, Z. F. Nanobarrier-Terminated Growth of Single-Walled Carbon Nanotubes on Quartz Surfaces. Nano Res. 2009, 2, 768-773.

69. Han, J.-H.; Graff, R. A.; Welch, B.; Marsh, C. P.; Franks, R.; Strano, M. S. A Mechanochemical Model of Growth Termination in Vertical Carbon Nanotube Forests. ACS Nano 2008, 2, 53-60.

70. Huaping, L.; Daisuke, T.; Shohei, C.; Yoshikazu, H. The Controlled Growth of Horizontally Aligned Single-Walled Carbon Nanotube Arrays by a Gas Flow Process. Nanotechnol. 2009, 20, 345604.

71. Zhang, R.; Zhang, Y.; Zhang, Q.; Xie, H.; Qian, W.; Wei, F. Growth of Half-Meter Long Carbon Nanotubes Based on Schulz-Flory Distribution. ACS Nano 2013, 7, 6156-6161.

72. Amama, P. B.; Pint, C. L.; McJilton, L.; Kim, S. M.; Stach, E. A.; Murray, P. T.; Hauge, R. H.; Maruyama, B. Role of Water in Super Growth of Single-Walled Carbon Nanotube Carpets. Nano Lett. 2008, 9, 44-49.

73. Reina, A.; Hofmann, M.; Zhu, D.; Kong, J. Growth Mechanism of Long and Horizontally Aligned Carbon Nanotubes by Chemical Vapor Deposition. J. Phys. Chem. C 2007, 111, 7292-7297.

74. Bedewy, M.; Farmer, B.; Hart, A. J. Synergetic Chemical Coupling Controls the Uniformity of Carbon Nanotube Microstructure Growth. ACS Nano 2014, 8, 5799-5812.

75. He, M.; Jiang, H.; Liu, B.; Fedotov, P. V.; Chernov, A. I.; Obraztsova, E. D.; Cavalca, F.; Wagner, J. B.; Hansen, T. W.; Anoshkin, I. V. et al. Chiral-Selective Growth of Single-Walled Carbon Nanotubes on Lattice-Mismatched Epitaxial Cobalt Nanoparticles. Sci. Rep. 2013, 3.

Table of Contents Graphic

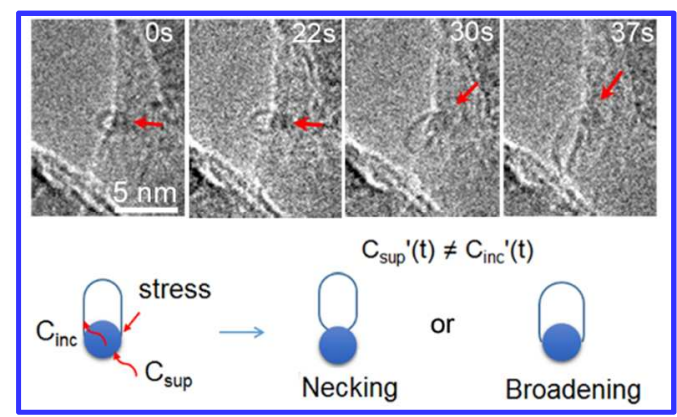

